\title{
Level of Knowledge About Prevention of Mother-to- Child Transmission of HIV Option B+ and Associated Factors Among ANC Clients in Kombolcha Town, South Wollo Amhara Regional State, Ethiopia, 2017
}

This article was published in the following Dove Press journal:

HIVIAIDS - Research and Palliative Care

\author{
Ayele Mamo Abebe (iD) \\ Mesfin Wudu Kassaw (iD ${ }^{2}$ \\ Nathan Estifanos \\ Shewangashaw ${ }^{3}$ \\ 'Department of Nursing, Debre Berhan \\ University, Amhara, Ethiopia; ${ }^{2}$ Department \\ of Nursing, College of Health Sciences, \\ Woldia University, Amhara, Ethiopia; \\ ${ }^{3}$ Department of Nursing, College of Health \\ Sciences, Wollo University, Amhara, \\ Ethiopia
}

\begin{abstract}
Purpose: The purpose of this study was to assess the level of knowledge about prevention of mother-to-child transmission option $\mathrm{B}+$ and associated factors among antenatal care clients in Kombolcha town; 2017.
\end{abstract}

Methods: An institutional-based cross-sectional study design was conducted from May 1 to 30, 2017. Simple random sampling techniques were used to select 129 study subjects from May 1 to 30,2017. A chi-square test was done by using SPSS 20 to assess the association between the dependent and independent variables. Frequency tables, pie chart, and graphs were used to present the findings of the study.

Results: Among the total study participants, $61 \%$ had adequate knowledge about prevention of mother-to-child transmission Option $\mathrm{B}+$. This study found a strong positive association between knowledge of prevention of mother-to-child transmission $\mathrm{B}+$ option and age, educational status, occupational status, number of ANC follow-up visits for the current pregnancy and number of parity.

Conclusion: This study showed more than half of these study participants had adequate knowledge about the prevention of mother-to-child transmission $\mathrm{B}+$ option. Age, educational status, employment, parity and number of antenatal care visits had a statistically significant association with pregnant womens' knowledge of prevention of mother-to-child transmission $\mathrm{B}+$ option. Therefore, it is better to design to give health education on prevention of mother-to-child transmission $\mathrm{B}+$ option particularly for older age, uneducated, unemployed, partiy of one pregnant women. Keywords: knowledge, factors, antenatal care, parity

\section{Introduction}

According to the WHO report, the global HIV/AIDS epidemic had claimed the lives of nearly 4.3 million children. ${ }^{1}$ Mother-to-child transmission (MTCT) is the largest source of HIV infection in children below the age of 15 years and affects approximately 500,000 infants per year globally, the majority of which are in emerging countries. ${ }^{2}$ The advantage of Option $\mathrm{B}+$ includes the improvement of maternal health and reduces the risk of HIV transmission to HIV negative male sexual partners. ${ }^{2,3}$

In 2020 an estimated 430,000 children were newly infected with HIV, nearly all of them through MTCT. Even in countries that are rapidly scaling up PMTCT services knowledge of pregnant women about PMTCT B + is a key for the success of the interventions HIV transmission from mother-to-child. ${ }^{4}$
Correspondence: Ayele Mamo Abebe Email ayelemamol2@gmail.com 
In 2013, the Ethiopian government adopted Option B + to substantially increase the provision of antiretroviral treatment to pregnant women living with HIV and aims to eliminate new HIV infections in children and keep their mothers alive $\&$ the mother and her child are followed up as a pair for up to 18-24 months. In Ethiopia, 1,216,908 people were living with HIV/AIDS and an estimated 90,311 HIV positive pregnant women are anticipated in $2010 .{ }^{6}$ In response to this, PMTCT programs are being started in many hospitals and health centers throughout the country, there are estimated 62,230 HIV positive pregnant women, 16,932 HIV positive births ( $62 \%$ of the country projection) and a total of 270,821 AIDS orphans in the region. ${ }^{7}$

Despite this fact, studies in Ethiopia and other Africa countries showed that PMTCT B + option utilization was low. A study done in Malawi shows that knowledge about PMTCT option B+ was low. ${ }^{8}$ Similarly, the finding of studies done in Gahanna, Tanzania, and Uganda indicated that only $25 \%, 35.2 \%$ and $30.1 \%$ pregnant women had adequate knowledge about PMTCT B+ options respectively. ${ }^{9-11}$

According to a study done in Hadiya, $94.6 \%$ of participants supposed that HIV infected pregnant women can transmit HIV to her fetus. About (54\%) of women were aware that not taking ARV drugs has its own negative effects on the prevention of HIV transmission from mother-to-child. Moreover, $92.1 \%$ of the respondents believed that good adherence could reduce the risk of opportunistic infections. ${ }^{12}$ Similarly, a study done in Addis Ababa indicated regarding mothers' knowledge of MTCT, 243 (70.4\%) participants knew the chance of transmission. ${ }^{13}$ Similarly, a study done in Jimma Town revealed that a small proportion of mothers (38.8\%) and (41.8\%) had sufficient knowledge about MTCT and PMTCT option B+, respectively. ${ }^{14}$ Based on the study done in Mekelle, $61.6 \%$ of women were aware that losing ARV drugs has its own negative effect on the prevention of HIV transmission from mother-to-child. In addition to this, $87 \%$ of participants believed that good adherence could reduce the risk of opportunistic infections. ${ }^{15}$

According to different studies conducted in Africa, age, employment, and educational status were associated with knowledge of pregnant women about the PMTCT B+ option. Odds of having inadequate knowledge about PMTCT B+ were significantly higher among older age, unemployed and uneducated pregnant women. ${ }^{10,14,16,17}$ Ethiopia's ANC service utilization coverage is the lowest one in the world (27.6\%). Similarly, the Amhara region has a lower ANC utilization rate $(26.5 \%)$ than in other regions in Ethiopia. ${ }^{18}$ The transmission of HIV from infected mothers to their infants ranges from
$15 \%$ to $25 \%$ in the developed nations and from $25 \%$ to $35 \%$ in emerging countries without any intervention. Generally, the transmission of HIV from mother-to-child has accounted for $15 \%$ to $45 \%{ }^{19}$ In Ethiopia, the past two decades HIV prevalence rate decreased from $3.3 \%$ in 2000 to $0.9 \%$ in 2017 , and AIDS-related deaths from 83000 deaths in 2000 to 15600 in $2017 .^{20}$

All-inclusive knowledge of AIDS is uncommon in Ethiopia. ${ }^{21,22}$ There are few studies done on knowledge of PMTCT in Ethiopia but there is published research on this title in the study area. Therefore, this study aimed to determine the Knowledge of pregnant women about the PMTCT $\mathrm{B}+$ option and identify factors associated with it.

\section{Methods and Materials Study Area and Period}

The study area was in Kombolcha town, situated eastern part of Amhara regional state in south Wollo zone, $380 \mathrm{~km}$ north of Addis Ababa. Kombolcha is far only $17 \mathrm{Km}$ from the capital city of south Wollo zone Dessie. They are four public health centers find in Kombolcha named as 03 health centers, 02 health centers, 05 health centers and 07 health centers. All of the four health centers have ANC follow-up clinic and provide PMTCT $\mathrm{B}^{+}$option services. An institutional-based cross-sectional study design was conducted from May 1 to 30, 2017.

\section{Source of Population}

All pregnant mothers who have ANC follow-up and lived in Kombolcha town.

\section{Study Population}

The study population for the study was all pregnant women who visited health center during the study period.

\section{Inclusion Criteria}

All pregnant mothers who were visiting ANC clinic were included

\section{Exclusion Criteria}

Severely ill pregnant mothers were excluded.

\section{Sample Size Determination}

Sample size determined by using single population proportion formula.

$$
\begin{aligned}
& =(1.96) 2 \times 0.5(1-0.5) /(0.05) 2=384 \\
& \mathrm{n}=\text { the required sample size } \\
& \mathrm{z}=\text { the value of the standard normal curve score } \\
& \text { corresponding to the given confidence interval }=1.96
\end{aligned}
$$


$\mathrm{p}=$ Prevalence of ANC follow up $=50 \%$

$\mathrm{d}=$ the permissible margin of error (the required precision) $=5 \%$

Since the total numbers 167 ANC clients were less than 10,000 , the desired sample size calculated using the following correction factor formula as follows: $n=n /(1+[n / N])$, where $\mathrm{N}=$ study population $\mathrm{n}=384 /(1+[384 / 167])=117$

By using $10 \%$ non-response rate, the total sample size was 129 .

\section{Sampling Procedure}

The simple random sampling method used to select participants. The Kombolcha town had four health centers. Then, by using population proportion to size each Kebele had its own sample size. Health center used as a sampling unit in this study. Finally, the lottery (simple random) method used to get the final sample size from each proportionally allocated sample size (Figure 1).

\section{Operational Definition of Variables}

Pregnant women Knowledge of PMTCT B ${ }^{+}$The knowledge of the women on Option B+ PMTCT was measured from the total number of correct answers to six knowledge questions, with a minimum score of 0 and maximum of 6 . The knowledge of the women on the Option B+ PMTCT program was considered "adequate" if they answered score greater than (60), and "inadequate" if they answered score less than $(<60 \%)$ of the knowledge questions, respectively.

Gravida or gravidity describes the total number of confirmed pregnancies that a woman has had, regardless of the outcome.

Para or parity is defined as the number of births that a woman has had after 20 weeks of gestation.

\section{Data Collection Tool and Procedure}

A questionnaire was adopted from the Joint United Nations Programmed on HIV/AIDS (UNAIDS). ${ }^{2,19}$ It was prepared in English and translated into Amharic and then translated back to English to check for its consistency. A questionnaire was pretested among $10 \%$ of the sample size on other health care facility. The questionnaire had included main points like socio-demographic characteristics, knowledge of PMTCT option B+ and health-related factors. Training was given for data collectors and supervisors. Supervisors and principal investigators have supervised the data collection process starting up to end.

\section{Data Quality Assurance}

The questionnaire was prepared in English and translated to Amharic and back to English. The questionnaire was pretested among $10 \%$ of the sample size in other place to avoid recall bias. The training was given for data collectors and supervisors. Supervisors were followed the data collection

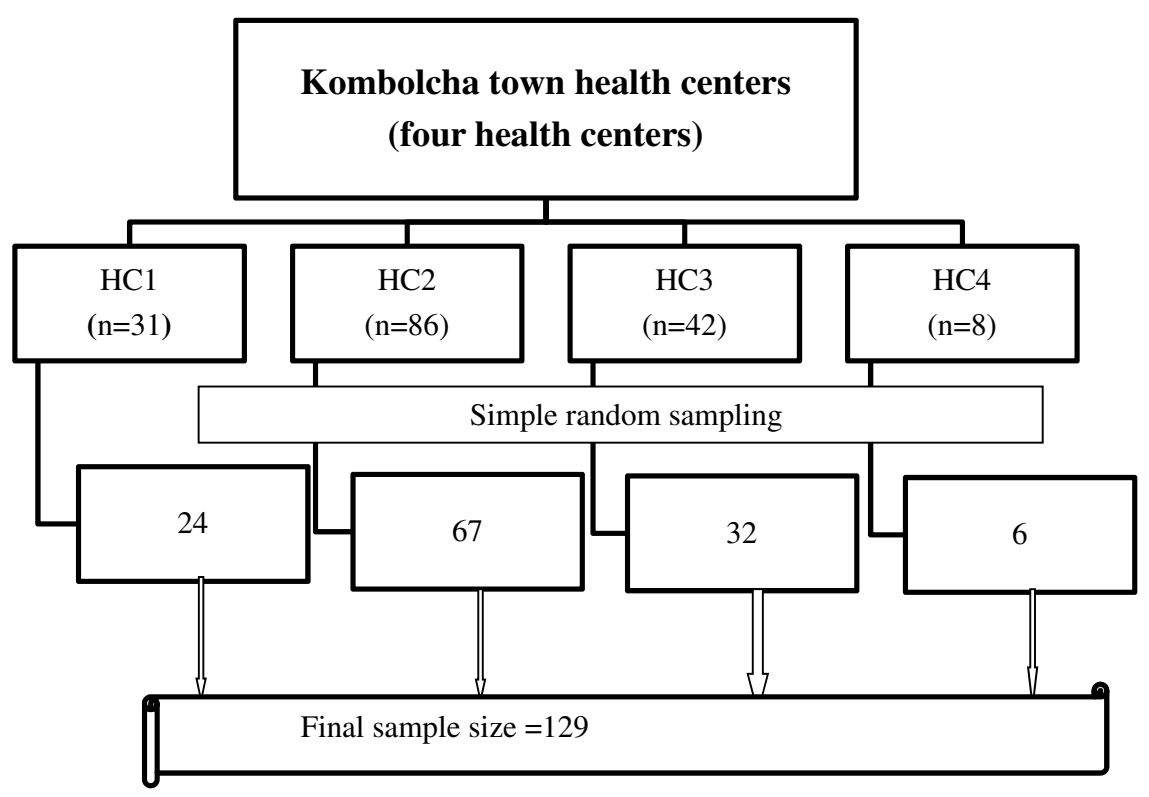

Figure I Schematic presentation of sampling procedure. 
process. Filled questionnaires were checked on a daily basis by investigators.

\section{Data Processing and Analysis}

Data entered into SPSS 20 and analyzed using SPSS Software version 20. Mean, Standard deviation, frequencies, percent and odds ratio calculated. Binary logistic regression analysis determined to assess the association between independent and dependent variables. Chi-square was done to assess the association between pregnant mother knowledge of PMTCT $\mathrm{B}^{+}$ option and independent variable. The Odds ratio was done to assess the strength of association. Frequency tables, graphs and pie charts were used to present the finding of the study.

\section{Result}

\section{Socio-Demographic Characteristics of the Study Participants}

From a total of 129 participants, 125(96.9\%) study participants participated in the study while 4 participants were unwilling to participate in the study. More than half of the respondents, $69(55.2 \%)$ study subjects were followers of Muslim. The predominant ethnic group in this study was Amhara 78 (62.4\%). The majority of the respondents (76 $(60.8 \%))$ were married, and $66(52.8 \%)$ of the study participants were employed (Table 1).

\section{Reproductive Related Characteristics of Participants}

Out of the total participants, 108 (86.4\%) study participants disclosed the result to their partner and103 (82.4\%) study subjects were multigravida. About 53(42.4\%) of this study participant had ANC follow up during their last pregnancy and Almost half (51.2\%) of these study subjects had 3 and more ANC visits in the health center for the current pregnancy (Table 2).

\section{Participants Knowledge of PMTCT Option $\mathrm{B}^{+}$}

Based on this study, $61 \%$ of participants had adequate knowledge about PMTCT Option $\mathrm{B}^{+}$(Figure 2).

\section{Factors Associated with Pregnant Women Knowledge of PMTCT Option $\mathrm{B}^{+}$}

Among these study participants, $43.2 \%$ of them were found within the age group of 25-34 years. This study had a strong positive association between knowledge of PMTCT $\mathrm{B}^{+}$
Table I The Socio-Demographic Characteristics of Participants in Kombolcha Town, Amahara, Ethiopia 2017/I8 ( $n=125)$

\begin{tabular}{|c|c|c|}
\hline Variables & Frequency $(n=125)$ & Percent (\%) \\
\hline \multicolumn{3}{|l|}{ Age } \\
\hline $15-24$ & 58 & 46.4 \\
\hline $25-34$ & 54 & 43.2 \\
\hline $35-49$ & 13 & 10.4 \\
\hline \multicolumn{3}{|l|}{ Educational status } \\
\hline Grade 9 and above & 48 & 38.4 \\
\hline Grade 5-8 & 33 & 26.4 \\
\hline Grade I-4 & 16 & 12.8 \\
\hline Able to read and write & 12 & 9.6 \\
\hline Unable to read and write & 16 & 12.8 \\
\hline \multicolumn{3}{|l|}{ Occupation } \\
\hline Employed & 66 & 52.8 \\
\hline Unemployed & 59 & 47.2 \\
\hline \multicolumn{3}{|l|}{ Marital status } \\
\hline Married & 76 & 60.8 \\
\hline Window & 30 & 24 \\
\hline Single & 19 & 15.2 \\
\hline \multicolumn{3}{|l|}{ Religion } \\
\hline Muslim & 69 & 55.2 \\
\hline Orthodox & 44 & 35.2 \\
\hline Protestant & 12 & 9.6 \\
\hline \multicolumn{3}{|l|}{ Ethnicity } \\
\hline Amhara & 78 & 62.4 \\
\hline Tigrie & 28 & 22.4 \\
\hline Afar & 13 & 10.4 \\
\hline Others* & 6 & 4.8 \\
\hline \multicolumn{3}{|l|}{ Male partner education } \\
\hline Literate & 103 & 82.4 \\
\hline Illiterate & 22 & 17.6 \\
\hline \multicolumn{3}{|l|}{ Transport fee } \\
\hline More than 5 birr & 58 & 46.4 \\
\hline Free & 67 & 53.6 \\
\hline
\end{tabular}

Notes: *Oromo, Gurage.

option and age $\left[\mathrm{P}=0.004\left(\mathrm{X}^{2}\right.\right.$ test $\left.\left.9.789 \mathrm{COR}=1.64\right)\right]$. Study subjects aged between 25 and 34 years were 3 times more likely to have adequate knowledge of PMTCT $\mathrm{B}^{+}$option as compared with those aged 35-49 years. The participants who have $\geq$ Grade 9 education status had shown an association with adequate knowledge of the PMTCT $\mathrm{B}^{+}$option $[\mathrm{P}=0.002$ $\left(\mathrm{X}^{2}\right.$ test 21.617 $\left.\left.\mathrm{COR}=2.00\right)\right]$.

Regarding the occupational status, employed participants were 27 times more likely to have adequate knowledge of the PMTCT $\mathrm{B}^{+}$option as compared with unemployed $[\mathrm{P}=0.001$ $\left(\mathrm{X}^{2}\right.$ test $\left.\left.70.614 \mathrm{COR}=26.875\right)\right]$.The pregnant mothers who 
Table 2 Reproductive Related Characteristics of Participants in Kombolcha, Amahara, Ethiopia 2017/18 $(n=125)$

\begin{tabular}{|c|c|c|}
\hline Variables & $\begin{array}{l}\text { Frequency } \\
(n=\mid 25)\end{array}$ & $\begin{array}{l}\text { Percent } \\
\text { (\%) }\end{array}$ \\
\hline \multicolumn{3}{|l|}{ Parity $(n=103)$} \\
\hline Greater than I & 41 & 32.8 \\
\hline I & 62 & 49.6 \\
\hline \multicolumn{3}{|l|}{ Number of pregnancies } \\
\hline Multigravida & 103 & 82.4 \\
\hline Primigravida & 22 & 17.6 \\
\hline \multicolumn{3}{|c|}{ ANC during the last pregnancy } \\
\hline Yes & 53 & 42.4 \\
\hline No & 72 & 57.6 \\
\hline \multicolumn{3}{|c|}{$\begin{array}{l}\text { Number of ANC visit for the current } \\
\text { pregnancy }\end{array}$} \\
\hline Greater than 3 & 64 & 51.2 \\
\hline 2 & 38 & 30.4 \\
\hline 1 & 23 & 18.4 \\
\hline \multicolumn{3}{|l|}{ HIV status disclosure } \\
\hline Yes & 108 & 86.4 \\
\hline No & 17 & 13.6 \\
\hline \multicolumn{3}{|l|}{ Male partner involvement } \\
\hline Yes & 102 & 81.6 \\
\hline No & 23 & 18.4 \\
\hline
\end{tabular}

had above 3 number of ANC visits for the current pregnancy were 1.53 times more likely to have adequate knowledge of PMTCT $\mathrm{B}^{+}$option as compared with other number of $\mathrm{AC}$ visits $\left[\mathrm{P}=0.021\left(\mathrm{X}^{2}\right.\right.$ test $\left.\left.6.789 \mathrm{COR}=1.53\right)\right]$. Similarly, mothers who had above one parity were 2.91 times more likely to have adequate knowledge of the PMTCT $\mathrm{B}^{+}$option as compared with counters $\left[\mathrm{P}=0.008\left(\mathrm{X}^{2}\right.\right.$ test 7.886 COR=2.91)] (Table 3).

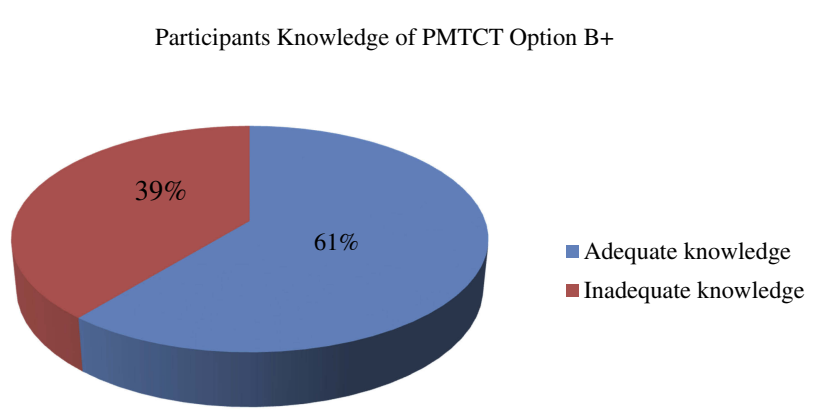

Figure 2 Level of knowledge about PMTCT Option $\mathrm{B}^{+}$among pregnant mothers in Kombolcha town, Amahara, Ethiopia, 2017.

\section{Discussion}

The study was aimed to assess Level of knowledge about prevention of mother-to-child transmission of HIV option $\mathrm{B}+$

Table 3 Factors Associated with Knowledge of Pregnant Women About PMTCT Option B ${ }^{+}$Kombolcha, Amhara, Ethiopia, 2017

\begin{tabular}{|c|c|c|c|c|c|}
\hline \multicolumn{6}{|c|}{ Adequate Knowledge of Pregnant Women About PMTCT B ${ }^{+}$Option } \\
\hline Variables $(n=125)$ & Yes & No & COR & $\begin{array}{l}\mathbf{X}^{2}{ }_{3.84} \\
\mathrm{cal}\end{array}$ & $P$ value \\
\hline \multicolumn{6}{|l|}{ Age } \\
\hline $15-24$ & 42 & 16 & 1.64 & 9.789 & 0.004 \\
\hline $25-34$ & 28 & 26 & 1.26 & & \\
\hline $35-49$ & 6 & 7 & 1 & & \\
\hline \multicolumn{6}{|l|}{ Education } \\
\hline$\geq$ Grade 9 & 32 & 16 & 2.00 & 21.617 & 0.002 \\
\hline $5-8$ & 20 & 13 & 1.978 & & \\
\hline $1-4$ & 10 & 6 & 2.14 & & \\
\hline Able to read and write & 7 & 5 & 1.8 & & \\
\hline Unable to read and write & 7 & 9 & 1 & & \\
\hline \multicolumn{6}{|l|}{ Occupational status } \\
\hline Employed & 60 & 6 & 26.875 & 70.614 & 0.001 \\
\hline Unemployed & 16 & 43 & 1 & & \\
\hline \multicolumn{6}{|l|}{ Transport fee } \\
\hline$>5$ birr & 29 & 29 & 0.72 & 0.976 & 0.314 \\
\hline Free & 39 & 28 & I & & \\
\hline \multicolumn{6}{|l|}{ ANC during the last pregnancy } \\
\hline Yes & 37 & 16 & 1.957 & 2.36 & 0.126 \\
\hline No & 39 & 33 & 1 & & \\
\hline \multicolumn{6}{|l|}{$\begin{array}{l}\text { No. ANC visit for the current } \\
\text { pregnancy }\end{array}$} \\
\hline$>3$ & 40 & 24 & 1.53 & 6.789 & 0.021 \\
\hline 2 & 24 & 14 & 1.57 & & \\
\hline 1 & 12 & 11 & 1 & & \\
\hline \multicolumn{6}{|l|}{ Parity $(n=103)$} \\
\hline$>1$ & 31 & 10 & 2.91 & 7.886 & 0.008 \\
\hline 1 & 32 & 30 & 1 & & \\
\hline \multicolumn{6}{|l|}{ Number of pregnancies } \\
\hline Multigravida & 66 & 37 & 2.14 & 2.87 & 0.172 \\
\hline Primigravida & 10 & 12 & 1 & & \\
\hline \multicolumn{6}{|l|}{ HIV status disclosure } \\
\hline Yes & 66 & 42 & 1.100 & 0.369 & 0.494 \\
\hline No & 10 & 7 & 1 & & \\
\hline \multicolumn{6}{|l|}{ Male partner involvement } \\
\hline Yes & 63 & 39 & 1.24 & 0.23 & 0.869 \\
\hline No & 13 & 10 & 1 & & \\
\hline \multicolumn{6}{|l|}{ Male partner education } \\
\hline Literate & 63 & 40 & 1.09 & 0.28 & 0.678 \\
\hline Illiterate & 13 & 9 & 1 & & \\
\hline
\end{tabular}


and associated factors among ANC clients in Kombolcha town. It was supposed that this study provided important information on level of knowledge about prevention of mother-to-child transmission of HIV option $\mathrm{B}+$ and associated factors among ANC clients in Kombolcha town.

According to this study, $61 \%$ of study subjects had adequate knowledge. The current study finding was higher than the finding of studies done in Gahanna (25\%), Tanzania (35.2\%), South Africa (23.1\%), and Uganda $(30.1 \%)^{9-11,22}$ and lower than the studies done in Malawi $(68 \%) .{ }^{8}$ This variation of findings across various studies might be due to cross-cultural limitations of diagnostic tools and reporting biases, differences in socio-economic environments. However, this study finding was comparable to studies done in Hadyia and Mekelle town which reported pregnant women knowledge of PMTCT $\mathrm{B}^{+}$were $59.9 \%$ and $56.7 \%$, respectively. ${ }^{12,15}$ This similarity might be due to cross-cultural similarity of diagnostic tools and similarity in socio-economic environments.

Based on our study, $43.2 \%$ of participants were found within the age group of 25-34 years. This implies majority of the antenatal attendees was within the age group of 25-34 years. According to EDHS 2011 national survey, the highest HIV prevalence was found in this age group (29-34 years). ${ }^{6}$ Therefore, directing a focus on this segment of the population is highly fertile for PMTCT of HIV prevention programmers in Ethiopia.

This study found a strong positive association between knowledge of PMTCT $\mathrm{B}^{+}$option and age $\left[\mathrm{P}=0.007\left(\mathrm{X}^{2}\right.\right.$ test 9.989 $\mathrm{COR}=2.83)$ ]. Study subjects aged between 25 and 34 years were 3 times more likely to had adequate knowledge of PMTCT $\mathrm{B}^{+}$option as compared with those aged 35-49 years. The finding was supported by studies done in Ethiopia, Tanzania and Gahanna. ${ }^{9,14,22}$ It was consistent with a research finding that showed older age women had lower level of knowledge on PMTCT. ${ }^{23}$ This similarity may be due to the use of social media in this age group since those age group were adult. The observed higher magnitude of adequate knowledge among lower age group might be explained as first since there is high expansion of education opportunity younger age may attain high level of education which contributes to their PMTCT $\mathrm{B}^{+}$option knowledge.

Another socio-demographic characteristic that had significant association with knowledge of PMTCT $\mathrm{B}^{+}$option in this study was education. The participants who have $\geq$ Grade 9 education status had shown association with adequate knowledge of PMTCT $\mathrm{B}^{+}$option $\left[\mathrm{P}=0.002\left(\mathrm{X}^{2}\right.\right.$ test 21.917 $\mathrm{COR}=2.00)$ ]. Similar relation was reported from studies done in Ethiopia, Nigeria and Tanzania. ${ }^{7,10,18}$ This implies improvement in women's educational status enables them to have better knowledge of PMTCT that decreases infant mortality and improve their health. The explanation may be due to the participants have secondary and above level of education might have chance to use social media and through they may get an opportunity to learn and know about PMTCT.

According to this study, employed participants were 27 times more likely to had adequate knowledge of PMTCT $\mathrm{B}^{+}$option as compared with unemployed $\left[\mathrm{P}=0.001\left(\mathrm{X}^{2}\right.\right.$ test $70.614 \mathrm{COR}=26.875)$ ]. This finding was agreed with reports of WHO 2014 and Malawi. ${ }^{1,8}$ The possible explanation may be that employment leads to adequate knowledge of PMTCT $\mathrm{B}^{+}$option in a number of ways. When women become unemployed, it is a stressful event that affects their self-esteem. Employment generates income plays a role on develop positive identity and improve the ability to follow healthy lifestyles like regular ANC visits, regular medical checkup and ask new information from health care provider which may raise their knowledge PMTCT, while unemployment leads to impoverishment, participate in health threatening coping behaviors such as negligence and missing ANC follow-up.

In this study, mothers who had above one parity were 2.91 times more likely to have adequate knowledge of PMTCT $\mathrm{B}^{+}$option as compared with counters $\left[\mathrm{P}=0.008\left(\mathrm{X}^{2}\right.\right.$ test $7.886 \mathrm{COR}=2 / 91)$ ]. This finding was not agreed with Addis Ababa study which indicated mothers who have many children ( $>5$ children) were found to be less knowledgeable about PMTCT than those that had lesser numbers of children. ${ }^{13}$ On the other hand, this finding was supported by studies conducted in Ethiopia. ${ }^{14,17}$ This may due to women who had multiple parity had high probability to visit health facility than the counterpart which may give opportunity to hear and know about PMTCT B ${ }^{+}$option.

Another important reproductive factor which had significant association with pregnant women knowledge of

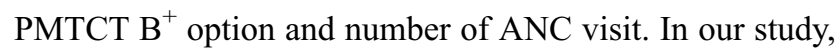
the pregnant mothers who had above 3 number of ANC visit for the current pregnancy were 1.53 times more likely to have adequate knowledge of PMTCT $\mathrm{B}^{+}$option as compared with other number of $\mathrm{AC}$ visits $\left[\mathrm{P}=0.021\left(\mathrm{X}^{2}\right.\right.$ test $6.789 \mathrm{COR}=1.53)]$. This finding was inlined the study done in Hawassa. ${ }^{6}$ The possible explanation may be due to the study subjects in two studies have 3 nad above ANC visits and this may increase their knowledge about the PMTCT. Also, this implies increasing pregnant 
women to have ANC seeking behavior enables them to have better knowledge of PMTCT $\mathrm{B}^{+}$option.

In this study marital status, HIV disclosure status, number of pregnancy, male partner involvement and husband occupational status had not statistically significant association with depression as other studies found out. ${ }^{5,14}$ This may be due to the small sample size in our study.

\section{Conclusion and Recommendation}

This study showed more than half study participants had adequate knowledge about PMTCT $\mathrm{B}+$ option. This is a small number respondent to get the expected change of PMTCT option $\mathrm{B}^{+}$in Ethiopia. On the other hand, age, educational status, employment, parity and number of ANC Visit had statistically significant association with pregnant women knowledge of PMTCT B + option. It better to design strategy to raise PMTCT B+ option knowledge of especially among prime Para women, uneducated and unemployed pregnant women and less number of ANC visit. Therefore, the health education should be given for those who have inadequate knowledge on PMTCT. Also, it is better to initiate early antenatal care visit through strong linkage with health post and health extension workers. This increases the knowledge of PMTCT for pregnant mothers.

\section{Abbreviations}

ANC, Antenatal Care; ART, Antiretroviral Therapy; ARV, Antiretroviral; CART, Combine Antiretroviral Therapy; CBC, Communication Behavioral Change; CDC, Communicative Disease Control; E-MTCT, Eliminate Mother-to-Child Transmission of HIV; HAART, Highly Active Antiretroviral Therapy; HIV, Human Immunodeficiency Virus; HTC, HIV Testing and Counseling; G.C, Gregorian Calendar; IEC, Information Education Communication; LTFU, Loss to Follow up; MNCH, Maternal Newborn and Child Health; $\mathrm{MOH}$ - Ministry of Health; NGO, NonGovernmental Organization; NVP, Nivirapine; OIs, Opportunistic Infections; PMTCT; Prevention of Mother-to-Child Transmission of HIV; UNAIDS, Joint United Nations Programme for HIV and AIDS; WHO, World Health Organization.

\section{Ethics Approval and Consent to Participate}

Ethical clearance was obtained from Wollo University, ethical review board and permission was given from
Kombolcha town health administrative office. The research proposal was evaluated and approved by the Research Ethics Review Committee [HRERC 0710/2017] of College of Health Sciences, Wollo University and ethical clearance was obtained. Official cooperation and permission was obtained from Kombolcha town health administrative office. Moreover, prior to commencing the study, a written informed consent was obtained from each respondent before data collection. In addition to this parental written consent was found from a parent of respondent. Confidentiality was maintained by omitting their name and personal identification of participant was no compelled to the study.

\section{Acknowledgment}

The authors would like to acknowledge Woldia University for providing sponsorship. Woldia town health Administrative office and all study participants in selected Kebeles are acknowledged for their cooperation during sample collection.

\section{Author Contributions}

All authors made substantial contributions to conception and design, acquisition of data or analysis and interpretation of data; took part in drafting the article or revising it critically for important intellectual content; gave final approval of the version to be published; and agree to be accountable for all aspects of the work.

\section{Disclosure}

The authors report no conflicts of interest in this work.

\section{References}

1. World Health Organization. Implementation of Option B+ for Prevention of Mother-to-Child Transmission of HIV: The Malawi Experience. 2014

2. HIV/AIDS, J.U.N.P. Global Report: UNAIDS Report on the Global AIDS Epidemic 2010. Geneva: UNAIDS; 2010.

3. World Health Organization. Consolidated Guidelines on the Use of Antiretroviral Drugs for Treating and Preventing HIV Infection: Recommendations for a Public Health Approach. World Health Organization; 2016.

4. Gourlay A, Birdthistle I, Mburu G, et al. Barriers and facilitating factors to the uptake of antiretroviral drugs for prevention of mother-to-child transmission of HIV in sub-Saharan Africa: a systematic review. J Int AIDS Soc. 2013;16(1):18588. doi:10.7448/ IAS.16.1.18588

5. Grede N, de Pee S, Bloem M. Economic and social factors are some of the most common barriers preventing women from accessing maternal and newborn child health $(\mathrm{MNCH})$ and prevention of mother-to-child transmission (PMTCT) services: a literature review. AIDS Behav. 2014;18(5):516-530. doi:10.1007/s10461-014-0756-5 
6. Central Statistical Agency and ICF International. Ethiopia Demographic and Health Survey 2011. Addis Ababa, Ethiopia and Calverton, Maryland, USA: Central Statistical Agency and ICF International; 2012:430.

7. Mitiku I, Arefayne M, Mesfin Y, et al. Factors associated with loss to follow-up among women in Option B+ PMTCT programme in northeast Ethiopia: a retrospective cohort study. J Int AIDS Soc. 2016;19 (1):20662. doi:10.7448/IAS.19.1.20662

8. Yeatman S, Trinitapoli J. Awareness and perceived fairness of option B+ in Malawi: a population-level perspective. J Int AIDS Soc. 2017;20(1):21467. doi:10.7448/IAS.20.1.21467

9. Boateng D, Kwapong GD, Agyei-Baffour P. Knowledge, perception about antiretroviral therapy (ART) and prevention of mother-to-childtransmission (PMTCT) and adherence to ART among HIV positive women in the Ashanti Region, Ghana: a cross-sectional study. $B M C$ Womens Health. 2013;13(1):2. doi:10.1186/1472-6874-13-2

10. Falnes EF, Tylleskär T, Paoli MM, et al. Mothers' knowledge and utilization of prevention of mother to child transmission services in northern Tanzania. $J$ Int AIDS Soc. 2010;13(1):36. doi:10.1186/17582652-13-36

11. Byamugisha R, Tumwine JK, Ndeezi G, et al. Attitudes to routine HIV counselling and testing, and knowledge about prevention of mother to child transmission of HIV in eastern Uganda: a cross-sectional survey among antenatal attendees. J Int AIDS Soc. 2010;13(1):52. doi:10.1186/1758-2652-13-52

12. Lodebo TM, Suloro JA. Level of adherence and associated factors to option B+ PMTCT among HIV positive pregnant women in Hadiya Zone, Southern Ethiopia. Glob J Health Sci. 2017;2(1):39-58.

13. Negash TG. Review of Prevention of Mother to Child Transmission of HIV in Addis Ababa, Ethiopia. University of South Africa; 2014.

14. Abajobir A, Zeleke A. Knowledge, attitude, practice and factors associated with prevention of mother-to-child transmission of HIV/ AIDS among pregnant mothers attending antenatal clinic in Hawassa referral hospital, South Ethiopia. J AIDS Clin Res. 2013;4(6):2-7. doi: $10.4172 / 2155-6113$
15. Ebuy H, Yebyo H, Alemayehu M. Level of adherence and predictors of adherence to the Option B+ PMTCT programme in Tigray, northern Ethiopia. Int $J$ Infect Dis. 2015;33:123-129. doi:10.1016/j. ijid.2014.12.026

16. Igwegbe A, Ilika A. Knowledge and perceptions of HIV/AIDS and mother to child transmission among antenatal mothers at Nnamdi Azikiwe University Teaching hospital, Nnewi. Niger J Clin Pract. 2005;8(2):97-101.

17. Deressa W, Seme A, Asefa A, et al. Utilization of PMTCT services and associated factors among pregnant women attending antenatal clinics in Addis Ababa, Ethiopia. BMC Pregnancy Childbirth. 2014;14(1):328. doi:10.1186/1471-2393-14-328

18. Malaju MT, Alene GD. Determinant factors of pregnant mothers' knowledge on mother to child transmission of HIV and its prevention in Gondar town, North West Ethiopia. BMC Pregnancy Childbirth. 2012;12(1):73. doi:10.1186/1471-2393-12-73

19. World Health Organization. Mother to Child Transmission of HIV. World Health Organization; 2011.

20. HAPCO. HIV prevention in Ethiopia National Road map. 2018. Available from: https://ethiopia.unfpa.org/en/.../hiv-preventionethiopia-national-road-map. Accessed February 10, 2020

21. WHO, 2015. Geneva: UNAIDS; 2011. Available from: http://www. unaids.org/en/media/unaids/contentassets/documents/unaidspublica tion/2011. Accessed February 10, 2020.

22. Bisnauth MA. Evaluation of the New Option B+ Pregnant Mother to Child Transmission (PMTCT) Program for HIV Infected Women at Hospital Facilities: Case Study at the Rahima Moosa Mother and Child Hospital. South Africa: Johannesburg; 2015.

23. Malaju MT, Alene GD. Determinant factors of pregnant mothers' knowledge on mother to child transmission of HIV and its prevention in Gondar town, North West Ethiopia. BMC Pregnancy Childbirth. 2012;12:73. doi:10.1186/1471-2393-12-73
HIV/AIDS - Research and Palliative Care

\section{Publish your work in this journal}

HIV/AIDS - Research and Palliative Care is an international, peerreviewed open-access journal focusing on advances in research in HIV, its clinical progression and management options including antiviral treatment, palliative care and public healthcare policies to control viral spread. The manuscript management system is completely online and includes a very quick and fair peer-review system, which is all easy to use. Visit http://www.dovepress.com/testimonials.php to read real quotes from published authors. 